\title{
Conhecimento em primeiros socorros: estudo comparativo entre professores de escola pública e privada
}

Knowledge of first aid: a comparative study among public and private school teachers

Conocimiento en primeros auxilios: estudio comparativo entre profesores de escuela pública y privada

André Luiz Alvim ${ }^{1 *}$, Cibele da Silva ${ }^{2}$, Deiane Patrício de Souza da Silva ${ }^{2}$, Renata Lacerda Prata Rocha².

\section{RESUMO}

Objetivos: Avaliar o conhecimento de professores atuantes no ensino fundamental de escola pública e privada, em relação aos primeiros socorros. Métodos: Estudo transversal, descritivo, de natureza quantitativa realizado em duas escolas, uma pública (escola A) e outra privada (escola B), localizadas em Belo Horizonte, MG, Brasil. Foi aplicado questionário estruturado para 63 professores, considerando o número de acertos $\geq 70 \%$ como satisfatório. Para tratamento dos dados, foi utilizada estatística descritiva simples e medidas de tendência central. A análise multivariada foi constituída pelo coeficiente de correlação de Pearson e regressão linear múltipla. Resultados: A pontuação dos professores da escola $A$ variou de 28,6 a 100 , com média de $66,8( \pm 20,7)$. Na escola B, os resultados alternaram entre 42,8 a 100 , com média de $81,9( \pm 17,5)$. O modelo final de regressão mostrou que os profissionais que receberam capacitação sobre primeiros socorros durante a graduação $(p=0,04)$ e os que atuam na escola privada $(p=0,01)$ tiveram melhor desempenho. Conclusão: O conhecimento em relação aos primeiros socorros precisa ser aprimorado entre professores da rede pública. O investimento em capacitações relacionadas à temática deve iniciar no período de formação acadêmica e se manter presente durante a rotina de trabalho.

Palavras-chave: Primeiros Socorros, Professores Escolares, Capacitação de Professores.

\section{ABSTRACT}

Objectives: To evaluate the knowledge that Teachers' working in primary education at public and private schools in relation to first aid. Methods: This was a cross-sectional, descriptive, quantitative study conducted in two schools, one public (school A) and one private (school B), located in Belo Horizonte, MG, Brazil. A structured questionnaire was applied to 63 teachers, considering the number of correct answers $\geq 70 \%$ as satisfactory. Data analysis was performed through the technique of descriptive statistics and measures of central tendency. The multivariate analysis consisted of the Pearson correlation coefficient and multiple linear regression. Results: The score of the teachers of the school A ranged from 28.6 to 100 , with a mean of 66.8 $( \pm 20.7)$. At school $B$, the results ranged from 42.8 to 100 , with a mean of $81.9( \pm 17.5)$. The final regression model showed that the professionals who received training on first aid during graduation $(p=0.04)$ and those who work in the private school $(p=0.01)$ performed better. Conclusion: Knowledge regarding first aid needs to be improved among public school teachers. The investment in training related to the subject must begin during the academic training period and remain present during the work routine.

Key words: Functional Foods, Diet, Chronic Disease.

${ }^{1}$ Faculdade UNA de Contagem, Contagem, MG, Brasil. *E-mail: andrealvim1@hotmail.com

${ }^{2}$ Centro Universitário UNA, Belo Horizonte, MG, Brasil.

SUBMETIDO EM: 5/2019

ACEITO EM: 6/2019

PUBLICADO EM: 7/2019

REAS/EJCH | Vol.Sup.27 | e1019 | DOI: https://doi.org/10.25248/reas.e1019.2019 Página 1 de 8 


\section{RESUMEN}

Objetivos: Evaluar el conocimiento de profesores actuantes en la enseñanza fundamental de escuela pública y privada en relación a los primeros auxilios. Métodos: Se trata de un estudio transversal, descriptivo, de naturaleza cuantitativa realizado en dos escuelas, una pública (escuela A) y otra privada (escuela B), ubicadas en la región de Belo Horizonte, MG, Brasil. Se aplicó un cuestionario estructurado para 63 profesores, considerando el número de aciertos $\geq 70 \%$ como satisfactorio. Para el tratamiento de los datos se utilizó estadística descriptiva y medidas de tendencia central. El análisis multivariado fue constituido por el coeficiente de correlación de Pearson y regresión lineal múltiple. Resultados: La puntuación de los profesores de la escuela A varió de 28,6 a 100, con promedio de 66,8 ( $\pm 20,7)$. En la escuela $B$, los resultados alternaron entre 42,8 a 100 , con un promedio de $81,9( \pm 17,5)$. El modelo final de regresión mostró que los profesionales que recibieron capacitación sobre primeros auxilios durante la graduación $(p=0,04)$ y los que actúan en la escuela privada $(p=0,01)$ tuvieron mejor desempeño. Conclusión: El conocimiento en relación a los primeros auxilios necesita ser mejorado entre profesores de la red pública. La inversión en capacitación relacionada con la temática debe iniciarse en el período de formación académica y mantenerse presente durante la rutina de trabajo.

Palabras clave: Primeros Auxilios, Maestros, Formación del Profesorado.

\section{INTRODUÇÃO}

A infância e adolescência tornam as pessoas mais susceptíveis a riscos, sendo a inquietude e a imprevisão inerentes ao crescimento. $\mathrm{O}$ ambiente escolar é um local propício aos acidentes devido grande número de estudantes que se encontram interagindo e desenvolvendo as mais diversas atividades cognitivas, motoras e esportivas (HARADA MJCS, 2012; OLIVEIRA IS, 2014)

As transformações sociais das famílias, com a inserção crescente da mulher no mercado de trabalho, contribuíram para introdução gradativa dos filhos no ambiente escolar. Diante disso, os alunos são considerados objetos de preocupação por parte dos profissionais que atuam nestes locais, exigindo preparo para lidar de forma adequada com situações de emergência, tais como parada cardiorrespiratória (PCR), convulsões, obstrução de vias aéreas e hemorragias (HARADA MJCS, 2012; OLIVEIRA IS, 2014; PERGOLA AM, ARAUJO IEM, 2008).

Segundo dados da Organização Mundial de Saúde (OMS), os acidentes ocupam uma das principais posições no ranking mundial de mortes dos 5 aos 19 anos. No Brasil, os acidentes escolares acometem um público pouco mais jovem, que varia de 1 a 14 anos, principalmente nas creches e pré-escolas (HARADA MJS, 2012; SILVA DP et al., 2018; WHO, 2008).

A conduta em situações de emergência deve ser rápida e eficaz de modo a afastar os riscos à vida. Por esse motivo, a educação em saúde deve ser entendida como uma prioridade no ambiente escolar, principalmente, no que tange aos primeiros socorros. Definido como a prestação de cuidados imediatos as vítimas de acidentes ou mal súbito, proporcionando a manutenção das funções vitais para redução das chances de agravamento até a chegada de uma assistência especializada (SILVA DP et al., 2018).

A educação em saúde, considerada ferramenta estratégica para prevenção de complicações e/ou óbitos decorrentes de acidentes escolares, deve promover autonomia e liberdade dos professores para realização de práticas positivas no primeiro atendimento a vítima (SILVA DP et al., 2018; MESQUITA T et al., 2017). Esses profissionais são considerados atores fundamentais, necessitando capacitá-los de forma contínua para as diversas situações emergenciais (CALANDRIM LF et al., 2017).

Crianças e adolescentes são mais vulneráveis, atribuindo às características do desenvolvimento físico e comportamental. Além disso, é importante salientar que o grupo das crianças possui vias aéreas mais estreitas, menor massa corporal e pele mais fina e suscetível a lesões - o que dificulta os primeiros socorros (CALANDRIM LF et al., 2017). 
$O$ atendimento inicial realizado de forma inadequada pode acarretar sérias complicações ao aluno vulnerável (BECKER KE, MOLINA FC, 2017). Destaca-se que são poucos professores que recebem capacitações contínuas em primeiros socorros, demonstrando que esses profissionais não estejam preparados suficientemente para lidar com as emergências escolares (CARVALHO LS, 2014). Através desta problemática, surgiu a seguinte inquietação: Qual é o conhecimento dos professores atuantes no ensino fundamental em relação aos primeiros socorros?

Este estudo torna-se relevante para difundir a temática entre os profissionais que atuam nas escolas de todo o país, incentivando o pensamento crítico-reflexivo sobre o preparo destes atores frente às diversas eventualidades. Os resultados poderão servir de base para construção de ações educativas em saúde para segurança do aluno, ampliando a base do conhecimento científico relacionado ao manejo correto das vítimas de acidentes. Por esse motivo, objetivou-se avaliar o conhecimento de professores atuantes no ensino fundamental de escola pública e privada em relação aos primeiros socorros.

\section{MÉTODOS}

Trata-se de um estudo transversal, descritivo, de natureza quantitativa que foi aprovado pelo Comitê de Ética e Pesquisa (CEP) através do número de parecer 3.175.005 e CAAE 08349019.7.0000.5098.

A pesquisa foi realizada em duas escolas, uma pública (escola $A$ ) e outra privada (escola B), localizadas em Belo Horizonte, MG, Brasil. A escola pública faz parte da região Noroeste e atende, aproximadamente, 773 alunos do município. No caso da escola privada, o atendimento é direcionado aos estudantes da região Norte, com conteúdo curricular voltado para a continuidade no ensino médio, com foco em cursos preparatórios pré-vestibulares.

No universo de 70 professores, $100 \%(n=50)$ atuantes na escola $A$ e $100 \%(n=20)$ na escola $B$, foram selecionados, respectivamente, $96 \%(n=48)$ e $75 \%(n=15)$, totalizando 63 participantes. $O$ tamanho da amostra foi estabelecido por uma estimativa para a proporção esperada considerando o erro amostral de $5 \%$, um nível de confiança de $95 \%$ e distribuição da população mais heterogênea (50/50) que exigiu uma amostra de no mínimo 60 profissionais.

Os critérios de inclusão foram: ser professor há mais de seis meses no local de estudo, ter experiência mínima de um ano na área educacional e atuar diretamente com alunos do ensino fundamental ( $1^{\circ}$ ao $9^{\circ}$ ano). Foram excluídos os profissionais que trabalham com alunos do ensino médio, que se encontram de férias, atestado médico ou que optaram pela não participação no estudo.

A coleta de dados foi realizada no mês de abril de 2019 por duas acadêmicas de enfermagem previamente treinadas, no turno matutino e vespertino, com duração total de duas semanas. Todos participantes leram e assinaram o Termo de Consentimento Livre Esclarecido (TCLE), permanecendo com uma cópia e entregando a segunda via aos aplicadores.

Inicialmente, foi construído um questionário estruturado pelos próprios pesquisadores com base na literatura e posteriormente, apresentado e validado por dois especialistas em urgência, emergência e traumatologia. O instrumento foi denominado "Questionário avaliativo em primeiros socorros" e possui 10 questões de múltipla escolha em relação às capacitações e vivências prévias, identificação e o atendimento de uma vítima de PCR, obstrução de vias aéreas por corpo estranho, cuidados em relação à convulsão, hemorragia nasal e ferimentos com sangramento abundante.

Todos os questionários foram corrigidos de forma manual, preservando a identidade e o sigilo dos participantes. A pontuação atribuída variou de 0 a 100 , adotando o ponto de corte $\geq 70 \%$ como satisfatório e $<70 \%$ insatisfatório.

As variáveis explicativas do estudo foram àquelas relacionadas às características sociodemográficas, tais como idade em anos, sexo, estado civil, tempo de trabalho e nível de escolaridade. Além dessas, foram incluídas as variáveis relacionadas ao questionário para avaliação do conhecimento em primeiros socorros. 
Destaca-se como variável resposta a pontuação final dos professores. Os resultados foram inseridos em um banco de dados por meio do programa Microsoft Excel $2013 \AA$. Inicialmente, houve análise exploratória dos dados e análise estatística descritiva para apresentações de valores absolutos e frequências relacionadas às características sociodemográficas e respostas do questionário. As medidas de tendência central foram utilizadas para as variáveis contínuas (idade em anos e pontuação final).

Para análise multivariada utilizou-se o coeficiente de correlação de Pearson e regressão linear múltipla, pois não houve normalidade entre os valores. Foi elaborado gráfico de dispersão para as variáveis estatisticamente significantes $(p<0,05)$ encontradas no modelo final. Todas as análises estatísticas foram realizadas através do software Epi Info® 7.2.

\section{RESULTADOS}

A idade dos participantes da escola A variou de 28 a 62 anos, com média de $46,3( \pm 8,9)$. Já na escola B variou de 26 a 51 , com média de 36,1 anos $( \pm 8,6)$.

A maioria dos participantes das duas escolas foi do sexo feminino, casada e com tempo de trabalho entre 5 e 10 anos. Em relação ao nível de escolaridade, destaca-se que $77 \%$ dos professores possuíam pósgraduação atuam diretamente na escola A (Tabela 1).

Tabela 1 - Características sociodemográficas dos participantes do estudo, Belo Horizonte, MG, Brasil (2019).

\begin{tabular}{|c|c|c|c|c|c|}
\hline \multirow[t]{2}{*}{ Variáveis } & \multicolumn{2}{|c|}{$\begin{array}{c}\text { Escola A } \\
(n=48)\end{array}$} & \multicolumn{2}{|c|}{$\begin{array}{c}\text { Escola B } \\
(n=15)\end{array}$} & \multirow[t]{2}{*}{ p-valor } \\
\hline & $\mathbf{n}$ & $\%$ & $\mathbf{N}$ & $\%$ & \\
\hline \multicolumn{6}{|l|}{ Sexo } \\
\hline Masculino & 12 & 25 & 5 & 33,3 & \\
\hline Feminino & 36 & 75 & 10 & 66,7 & \\
\hline \multicolumn{6}{|l|}{ Estado civil } \\
\hline Casado & 27 & 56,3 & 8 & 53,3 & \\
\hline Divorciado & 10 & 20,8 & 3 & 20 & \\
\hline Solteiro & 10 & 20,8 & 4 & 26,7 & \\
\hline Viúvo & 1 & 2,1 & - & - & $>0,05$ \\
\hline \multicolumn{6}{|c|}{ Tempo de trabalho (anos) } \\
\hline Até 5 & 16 & 33,3 & 6 & 40 & \\
\hline 6 a 10 & 17 & 35,4 & 6 & 40 & \\
\hline $11+$ & 15 & 31,3 & 3 & 20 & \\
\hline \multicolumn{6}{|c|}{ Nível de escolaridade } \\
\hline Graduação & 11 & 22,9 & 8 & 53,3 & \\
\hline Pós-graduação & 37 & 77,2 & 7 & 46,7 & \\
\hline
\end{tabular}

Fonte: Dados da pesquisa, 2019.

A maioria dos professores não foi capacitada durante a formação acadêmica em relação aos primeiros socorros.

Os profissionais da escola A $(97,9 \%)$ e B $(86,7 \%)$ afirmaram não ter recebido treinamentos recentes no ambiente de trabalho. 
Grande parte dos professores já presenciou alguma situação de emergência no ambiente escolar. Destacou-se que a maior dificuldade foi atrelada aos professores da escola $\mathrm{A}$ no que diz respeito à definição de PCR (62,5\%), ao atendimento a vítima de convulsão (60,4\%), a identificação correta de uma PCR $(52,1 \%)$ e aos cuidados indicados durante sangramento abundante $(47,9 \%)$ (Tabela 2).

Tabela 2 - Análise descritiva das variáveis do questionário para avaliação dos professores em relação aos primeiros socorros, Belo Horizonte, MG, Brasil (2019).

\begin{tabular}{|c|c|c|c|c|}
\hline \multirow[t]{2}{*}{ Variáveis } & \multicolumn{2}{|c|}{ Escola A $(n=48)$} & \multicolumn{2}{|c|}{$\begin{array}{c}\text { Escola B } \\
(n=15)\end{array}$} \\
\hline & $\mathbf{n}$ & $\%$ & $\mathbf{n}$ & $\%$ \\
\hline \multicolumn{5}{|l|}{$\begin{array}{l}\text { 1. Você recebeu capacitação sobre primeiros socorros durante a } \\
\text { formação acadêmica (graduação)? }\end{array}$} \\
\hline Não & 36 & 75 & 13 & 86,7 \\
\hline \multicolumn{5}{|l|}{$\begin{array}{l}\text { 2. Você participou de treinamentos sobre primeiros socorros na sua } \\
\text { instituição atual? }\end{array}$} \\
\hline Não & 47 & 97,9 & 13 & 86,7 \\
\hline \multicolumn{5}{|l|}{$\begin{array}{l}\text { 3. Você já presenciou alguma situação de emergência envolvendo } \\
\text { alunos no ambiente escolar? }\end{array}$} \\
\hline Sim & 26 & 54,2 & 11 & 73,3 \\
\hline \multicolumn{5}{|l|}{ 4. Primeiros socorros dizem respeito a: } \\
\hline $\begin{array}{l}R=\text { Prestação de cuidados imediatos à vítima por uma pessoa } \\
\text { capacitada até a chegada de atendimento médico especializado. }\end{array}$ & 47 & 97,9 & 15 & 100 \\
\hline \multicolumn{5}{|l|}{ 5. Defina Parada Cardiorrespiratória: } \\
\hline $\begin{array}{l}R=E \text { É a cessação da atividade mecânica do coração confirmada pela } \\
\text { ausência de sinais de circulação e respiração. }\end{array}$ & 30 & 62,5 & 11 & 73,3 \\
\hline \multicolumn{5}{|l|}{ 6. Como identificar uma Parada Cardiorrespiratória? } \\
\hline$R=A$ vítima não está responsiva, não respira e está sem pulso. & 25 & 52,1 & 10 & 66,7 \\
\hline \multicolumn{5}{|l|}{ 7. Como proceder durante uma situação de engasgamento? } \\
\hline $\begin{array}{l}R=\text { Posicionar-se atrás da vítima e iniciar as manobras de } \\
\text { compressão abdominal, conhecida como Manobra de Heimlich. }\end{array}$ & 33 & 70,1 & 13 & 86,7 \\
\hline \multicolumn{5}{|l|}{ 8. No atendimento à vítima de convulsão, o socorrista deve: } \\
\hline $\begin{array}{l}R=\text { Procurar deitar a vítima protegendo sua cabeça, lateralizá-la, e } \\
\text { logo depois da crise, liberar as vias aéreas. }\end{array}$ & 29 & 60,4 & 13 & 86,7 \\
\hline \multicolumn{5}{|l|}{ 9. No caso de hemorragia nasal, qual atitude deve ser tomada? } \\
\hline $\begin{array}{l}R=\text { Comprimir as narinas e aplicar uma compressa com gelo sobre } \\
\text { o nariz. }\end{array}$ & 40 & 83,3 & 12 & 80 \\
\hline \multicolumn{5}{|l|}{$\begin{array}{l}\text { 10. O cuidado indicado durante sangramento abundante } \\
\text { (hemorragia) é: }\end{array}$} \\
\hline$R=$ Realizar compressão no local. & 23 & 47,9 & 12 & 80 \\
\hline
\end{tabular}

Fonte: Dados da pesquisa, 2019.

Em relação aos resultados do questionário, a pontuação da escola A variou de 28,6 a 100, com média de $66,8( \pm 20,7)$. Na escola B, os resultados alternaram entre 42,8 a 100 , com média de $81,9( \pm 17,5)$.

O modelo de regressão linear múltipla mostrou que os profissionais que receberam capacitação em primeiros socorros durante a formação acadêmica $(p=0,04)$ e os que atuam na escola privada $(p=0,01)$ tiveram melhor conhecimento em primeiros socorros. Houve correlação positiva entre as variáveis explicativas e a pontuação final dos professores (Figura 1). 
Figura 1 - Scatter plot sobre as curvas de regressão linear da pontuação do questionário, associadas às variáveis de capacitação sobre PS durante a graduação e o tipo de escola, Belo Horizonte, MG, Brasil (2019).
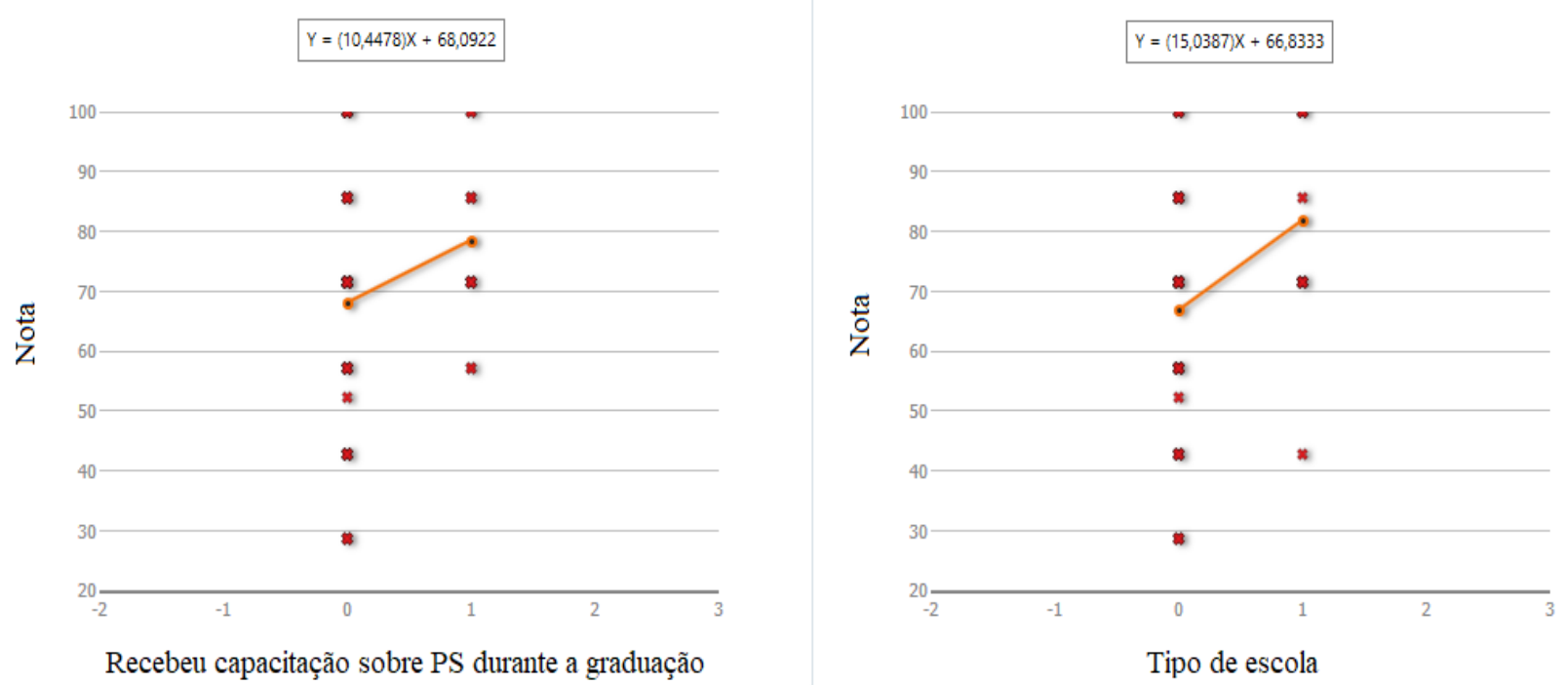

Fonte: Dados da pesquisa, 2019.

\section{DISCUSSÃO}

Um acidente, além de trazer transtornos aos envolvidos pode acarretar problemas de responsabilidade legal. Diante disto, a omissão de socorro, caracterizada como deixar de prestar assistência ou não pedir o socorro de autoridade pública, configura-se indiscutivelmente como um crime que fere o código penal (CABRAL EV, OLIVEIRA MFA, 2017).

Para situações de emergência com crianças e adolescentes foi publicada a Lei 13.722, de 4 de outubro de 2018, que entrou em vigor no dia 2 de abril de 2019. Essa normativa tornou obrigatória a capacitação de professores e funcionários da educação básica e recreação infantil no que diz respeito à temática, seja estabelecimento de ensino público ou privado (BRASIL, 2018).

Nesse contexto, a análise descritiva mostrou que a maioria dos professores não foi capacitada previamente em relação aos primeiros socorros. Estudo realizado na Etiópia encontrou dados similares, afirmando a necessidade de considerar a inclusão do tema no currículo acadêmico (GANFURE G et al., 2018).

Nos cursos de licenciatura, com raras exceções, não se fazem vigente uma disciplina que aborde a temática. Tal fato pode ser modificado através de novos projetos pedagógicos validados pelo Ministério da Educação, exigindo consolidação durante o período de formação acadêmica (CHAVES AFL et al., 2018; SILVA DP et al., 2018).

Os dados deste estudo mostraram que grande parte dos professores já presenciou situações de emergência no ambiente escolar. Estudo reforçou que o conhecimento prévio dos educadores através de capacitações e treinamentos contribui para o manejo eficaz dos primeiros socorros (GALINDO NNM, CARVALHO GCN, CASTRO RCMB et al., 2018).

Infere-se que o processo ativo de ensino-aprendizagem promove a melhora do desempenho e da habilidade, tornando o treino prático em primeiros socorros uma peça-chave fundamental para a formação de multiplicadores do conhecimento (KAWAKAME PMG, MIYADAHIRA AMK, 2015).

Reportando-se a identificação correta da PCR foi notória dificuldade atrelada ao conhecimento dos professores. Pesquisas realizadas no Brasil e Nigéria apontaram conhecimento insatisfatório no ambiente escolar em relação às práticas de ressuscitação cardiopulmonar (MESQUITA T et al., 2017; ONYEASO AO ONYEASO OO, 2017). 
Tal agravo exige ação rápida, ordenada e sistematizada para que se obtenha êxito no restabelecimento das funções vitais. Neste caso, o conhecimento inadequado pode influenciar negativamente as taxas de sobrevivência, acarretando danos neurológicos irreversíveis (SILVA DP et al., 2018; CABRAL EV, OLIVEIRA MFA, 2017; CARMO HO et al., 2017).

Outro ponto diz respeito aos professores da escola A que, apresentaram pontuação abaixo dos $70 \%$ em relação aos casos de convulsão. Vale à pena ressaltar que este fenômeno promove perda da consciência associada às contraturas musculares involuntárias parciais ou generalizada, exigindo precauções específicas para prevenção de danos. Com isso, os profissionais necessitam aprimorar as condutas no que tange à proteção da cabeça, lateralização do corpo e liberação de vias aéreas (FIORUC BE, MOLINA AC, JUNIOR WV et al., 2008).

O pior desempenho foi atribuído aos casos de sangramento abundante envolvendo alunos, onde os resultados evidenciaram despreparo dos professores da escola A. Onde na maioria das vezes, os profissionais optam por chamar o Serviço de Atendimento Médico de Urgência (SAMU) devido associação do atendimento especializado à elevação da taxa de sobrevivência (GALINDO NNM, CARVALHO GCN, CASTRO RCMB et al., 2018). Porém, a espera prolongada pode causar sérios danos à vítima, como por exemplo, o choque hipovolêmico.

O modelo de regressão linear múltipla mostrou que os professores capacitados durante o período de formação acadêmica e os que atuam na escola privada tiveram melhor pontuação avaliativa. Estudo realizado na Turquia encontrou associação entre a variável explicativa e o conhecimento satisfatório, atribuindo o resultado positivo a educação em saúde recebida pelos profissionais durante a graduação. Além disso, as escolas privadas tiveram melhor desempenho de práticas positivas e atitudes proativas relacionadas aos primeiros socorros (GANFURE G et al., 2018).

Infere-se que um maior investimento em formação prévia e valorização das capacitações - não se esquecendo dos professores da rede pública, promoverá atendimento qualificado por meio de técnicas seguras e apropriadas para lidar com as situações de emergência (FIORUC BE, MOLINA AC, JUNIOR WV et al., 2008).

Este estudo possui algumas limitações que devem ser reconhecidas. A coleta de dados foi realizada no intervalo das aulas, influenciando o tempo para as respostas do questionário. Além disso, a concentração dos participantes pode ter sido influenciada pelo barulho excessivo dos alunos gerado nos momentos de recreação e lazer.

\section{CONCLUSÃO}

O conhecimento em relação aos primeiros socorros precisa ser aprimorado entre professores da rede pública e àqueles que não tiveram capacitações durante o período de formação acadêmica. $O$ investimento no processo de ensino-aprendizagem permitirá qualificar o atendimento à vítima até a chegada de um serviço especializado. No entanto, essa temática ainda é pouco conhecida e valorizada entre os professores, exigindo novas estratégias educativas para redução de complicações e/ou óbitos advindos de emergências escolares.

Os resultados poderão contribuir para que as ações educativas em saúde sejam planejadas com o intuído de promover a segurança no ambiente escolar. É necessário que os gestores incentivem a formação de professores, e quem sabe, revejam a possibilidade de acrescentar os primeiros socorros como temática obrigatória no plano pedagógico curricular.

\section{AGRADECIMENTOS E FINANCIAMENTO}

Agradecemos ao Centro Universitário UNA, especialmente, às coordenadoras Rozilene Francisca de Lima e Hyorrana Pereira (Faculdade UNA de Contagem). Afirmamos que este estudo não recebeu financiamentos.

REAS/EJCH | Vol.Sup.27 | e1019 | DOI: https://doi.org/10.25248/reas.e1019.2019 Página 7 de 8 


\section{REFERÊNCIAS}

1. BECKER KE, MOLINA FC. Primeiros Socorros nas Escolas: opção ou necessidade. SIEDUCA. 2017.

2. BRASIL. Lei no 13.722 de 04 de outubro de 2018. Torna obrigatória a capacitação em noções básicas de primeiros socorros de professores e funcionários de estabelecimentos de ensino públicos e privados de educação básica e de estabelecimentos de recreação infantil. Brasília, 2018.

3. CABRAL EV, OLIVEIRA MFA. Primeiros socorros na escola: conhecimento dos professores. Ensino, Saúde e Ambiente. 2017; 10 (1): 175-86.

4. CALANDRIM LF. et al. First aid at school: teacher and staff training. Rev Rene. 2017; 18(3): 292-9.

5. CARMO HO. et al. Atitudes dos docentes de educação infantil em situações de acidente escolar. Revista de Enfermagem do Centro-Oeste Mineiro. 2017; 7: 1457.

6. CARVALHO LS. et al. A Abordagem de Primeiros Socorros Realizada pelos Professores em uma Unidade de Ensino Estadual em Anápolis. Ensaios Cienc Cienc Biol Agrar Saúde. 2014; 18(1): 25-30.

7. CHAVES AFL. et al. Reanimação cardiopulmonar nas escolas: avaliação de estratégia educativa. Revista Expressão Católica Saúde. 2018; 2(1): 65-72.

8. FIORUC BE, MOLINA AC, JUNIOR WV. et al. Educação em Saúde: abordando primeiros socorros em escolas públicas no interior de São Paulo. Rev Eletr Enf. 2008; 10(3): 695-702.

9. GALINDO NNM, CARVALHO GCN, CASTRO RCMB. et al. Vivências de professores acerca dos primeiros socorros na escola. Rev Bras Enferm. 2018; 71(Suppl4): 1678-84.

10. GANFURE G. et al. First aid knowledge, attitude, practice, and associated factors among kindergarten teachers of Lideta sub-city Addis Ababa, Ethiopia. PLoS One. 2018; 13(3): e0194263.

11. HARADA MJCS. Injúrias físicas não intencionais na infância e adolescência. In: Harada MJCS, Pedreira MLG, Viana DL. Promoção da saúde. São Caetano do Sul: Yendis Editora, 2012.

12. KAWAKAME PMG, MIYADAHIRA AMK. Assessment of the teaching-learning process in students of the health area: cardiopulmonary resuscitation maneuvers. Rev esc enferm USP. 2015; 49(4): 0657-64.

13. MESQUITA T. et al. Recurso educativo em primeiros socorros no processo ensino-aprendizagem em crianças de uma escola pública. RCP. 2017; 3(1): 35-0.

14. OLIVEIRA IS. et al. Knowledge of educators on prevention of accidents in childhood. Rev Enferm UFPE. 2014; 8(2): 279-85.

15. ONYEASO AO, ONYEASO OO. Comparison of Practicing and Student Teachers' Knowledge of Cardiopulmonary Resuscitation in Nigeria. Public Health Res. 2017; 7(6): 143-7.

16. PERGOLA AM, ARAUJO IEM. O leigo em situação de emergência. Rev esc enferm USP. 2008; 42(4): 769-76.

17. SILVA DP, et al. Primeiros socorros: objeto de educação em saúde para professores. Rev enferm UFPE online. 2018; 12(5): 1444-53.

18. WHO. WORLD HEALTH ORGANIZATION. World report on child injury prevention/edited by Margie Peden [et al]. WHO Press, 2008. 